\title{
Treatment of Distal Femoral Fractures by Retrograde Nail Versus Minimally Invasive Percutaneous Plate Osteosynthesis: A Comparative Study \\ Abdelsalam Mohammed Hefny, Yuosuf Mohammed Khira, Ashraf AbdEldayem Mohamed, and *Mohammed Nasr Mahmoud Mousa \\ Department of Orthopedic Surgery, Faculty of Medicine, Zagazig University, Egypt \\ *Corresponding Author: Mohammed Nasr Mahmoud Mousa, Tel : (+20) 1066991710, email: sokarmobile@ gmail.com
}

\begin{abstract}
:
Background: Distal femoral fractures are serious injuries and represent a real challenge as regards their management.

Objectives: The purpose of this study was to assess the results of treatment of distal femoral fractures by retrograde intramedullary nail versus minimally invasive locking compression plate.

Patients and methods: This is a retrospective study that included 20 patients with distal femoral fractures; 10 of them treated by retrograde nail (group A) and the remainder treated by locked plate using minimally invasive plate osteosynthesis technique (group B) at El-Hadra University Hospital and Kafr-Eldawar General Hospital from AUG 2016 till AUG 2018.

Results: In group A, the results were excellent in 2 patients (20.0\%), good in $3(30.0 \%)$, fair in $3(30.0 \%)$ and poor 2 patients $(20.0 \%)$. In group B, the result was excellent in one patient $(10.0 \%)$, good in 4 patients $(40.0 \%)$, fair in 3 patients $(30.0 \%)$ and poor in 2 patients $(20.0 \%)$. There was no significant statistical difference regarding final score in the two studied groups $(\mathrm{P}<0.05)$.

Conclusions: It could be concluded that retrograde nailing provides a good intramedullary stability and firm callus and may be effectively implanted in segmental fractures of the distal femur. unrelenting knee pain and inability to move the knee in type $\mathrm{C}$ fractures are the main limiting factors of retrograde nail. $\mathrm{LCP}$ was associated with less morbidity in terms of persistent knee pain and better range of movements than retrograde nailing. Locked plating may be utilized for all distal femur fractures including type $\mathrm{C}$ fractures and osteoporotic fractures.
\end{abstract}

Keywords: Distal femoral fractures, Locking plate (LCP), Retrograde nail (RGN).

\section{INTRODUCTION}

Distal femur fractures occur at approximately one-tenth the rate of proximal femur fractures and make up to $6 \%$ of all femur fractures. It's noticed that there is a bimodal distribution of fractures based on age and gender. Most high-energy distal femur fractures occur in males (median age 65.6). While most of low-energy fractures occur in osteoporotic women (median age 71). Injury caused through highenergy mechanisms were more common in men $(70.5 \%)$ whilst women sustained injuries mainly from low-energy mechanisms $(82.7 \%)(\mathrm{p}<0.0001)^{[1]}$.

There are many factors make the final results of treatment of these fractures unsatisfactory in many cases (Fracture type, associated injuries, patient age, premorbid medical status, soft tissue injury, and the possible neurovascular injuries). This reflects the challenges that face the orthopedic surgeons during the course of treatment, whether by conservative or surgical methods ${ }^{[2]}$.

Long-term disability can still occur in patients with extensive articular cartilage damage, marked bone comminution, and severe soft tissue injury ${ }^{[3,4]}$.

Historically, the treatment of distal femur fractures has not produced a high percentage of excellent clinical results. Thin cortices, osteoporosis, a wide intramedullary canal, and fracture comminution have made stable fixation of these injuries difficult to achieve and maintain with traditional operative methods ${ }^{[5]}$.

Problems with ordinary open reduction and internal fixation by plate for the distal femoral fractures are well established. These problems have been associated with the extensile exposures of the fracture site ${ }^{[6]}$. Because anatomical reduction and immediate motion of the limb was sought by surgeons, the merits of stabilization techniques were based additionally on mechanical factors than biological considerations. Precise, direct reduction and rigid stabilization had their biological consequences; a loss of bone perfusion, a decreased rate of fracture vascularization, and an increased susceptibility to infection ${ }^{[7]}$.

The purpose of this study was to assess the results of treatment of distal femoral fractures by retrograde intramedullary nailing versus minimal invasive locking compression plates.

\section{PATIENTS AND METHODS}

This retrospective study included a total of 20 patients with distal femoral fractures, attending at ElHadra University Hospital, Alexandria and kafrEldawar General Hospital. Written informed consent of all the subjects and/or their caregivers was obtained. This study was conducted between AUG 2016 till AUG 2018. 


\section{Ethical approval}

Approval of the ethical committee and Institutional Review Board (IRB) was obtained. This study followed the principles of the Declaration of Helsinki for studies involving humans.

The included subjects were divided into two groups; Group A consisted of 10 patients treated by retrograde nail and Group B consisted of 10 patients treated by locked plate using minimally invasive plate osteosynthesis technique.

In group A the mean age of patients was 40.9 (28$60)$ years. Eight patients were males $(80 \%)$ and 2 patients were females $(20 \%)$. seven patients $(70.0 \%)$ had their fractures due to severe trauma (RTA or FFH) and 3 patients (30.0\%) due to mild to moderate trauma (falling down). All of them (100\%) had type $\mathrm{A}$ fracture according to AO classification. The mean time before surgery was 5.4 days. In group B the mean age of patients was $41.7(24-52)$ years. Seven patients were males $(70.0 \%)$ and 3 patients $(30.0 \%)$ were females. Eight patients $(80 \%)$ had their fractures due to severe trauma and 2 patients $(20 \%)$ due to mild to moderate trauma. 7 patients $(70.0 \%)$ had type A fracture and 3 patients $(30.0 \%)$ had type $\mathrm{C}$ fracture according to $\mathrm{AO}$ classification. The mean time before surgery was 3.4 days.

Patients were subjected to clinical and radiological examination in order to collect the data needed for analysis of the results. Every patient was examined clinically for the following data: limping, pain, evidence of infection, deformities, limb length discrepancy and range of knee motion. Anteroposterior and lateral views of the lower femur and the knee were done for every patient at the time of follow up, in addition to the preoperative and immediate postoperative x-rays. Assessment of the union, displacement, angulations and implant failure were done by observing these $\mathrm{x}$-rays.

\section{Statistical analysis}

Data were fed to the computer and analyzed using IBM SPSS software package version 20.0. Qualitative data were described using number and percent. Quantitative data were described using range (minimum and maximum), mean, standard deviation and median. Significance of the obtained results was judged at the $5 \%$ level.

The used tests were: Chi-square test, Fisher's Exact or Monte Carlo correction, Student t-test and Z Mann Whitney test

\section{RESULTS}

Age in group A ranged 28-60 with mean value $40.90 \pm 11.28$ and in group B ranged 24-52 with mean value $41.70 \pm 9.72$. Males in group A were $8(80 \%)$ and females were $2(20 \%)$ while in group B, males were $7(70 \%)$ and females were $3(30 \%)$. There was no significant statistical difference regarding age and sex in the two studied groups $(\mathrm{P}>0.05)$. Table (1)

Time of union was less than 3 months in 8 patients (80.0\%)in group A and more than 3 months in 2 patients $(20.0 \%)$ while in group B, the time was less than 3 months in 7 patients(70.0\%) and more than 3 months in 3 patients $(30.0 \%)$. There was no significant statistical difference regarding time of union in the two studied groups $(\mathrm{P}>0.05)$. Table (2)

No shortening in group A was found in 8 patients $(80.0 \%)$ and shortening $(>2 \mathrm{~cm})$ in 2 patients (20.0\%). While in group B, no shortening was 7 patients $(70.0 \%)$ and shortening $(>2 \mathrm{~cm})$ in 3 patients $(30.0 \%)$. There was no significant statistical difference regarding shortening in the two studied groups $(\mathrm{P}>0.05)$ Table (3)

In group $\mathrm{A}$, the results were excellent in 2 patients (20.0\%), good in $3(30.0 \%)$, fair in $3(30.0 \%)$ and poor 2 patients $(20.0 \%)$. In group B, the result was excellent in one patient $(10.0 \%)$, good 4 patients $(40.0 \%)$, fair 3 patients $(30.0 \%)$ and poor 2 patients $(20.0 \%)$. There was no significant statistical difference regarding final score in the two studied groups $(\mathrm{P}<0.05)$ Table (4).

Clinical cases: A 24-year-old male patient had AO type A1 fracture of his left distal femur with after falling from height. He was operated 3 days following the initial trauma where both fractures were fixed by minimally invasive locking plate and ORIF respectively. He presented 18 months after surgery; he had full range of motion in his knee with no associated complications. His final score was excellent. Figures $1 \mathrm{a}, 1 \mathrm{~b}$ and $1 \mathrm{c}$. 
Table (1): Comparison between the two studied groups according to the age (years)

\begin{tabular}{||l|l|l|l|l|l|l||}
\hline \multirow{2}{*}{ Age (years) } & \multicolumn{2}{l|}{$\begin{array}{l}\text { Group A } \\
(\mathbf{n = 1 0})\end{array}$} & \multicolumn{2}{l|}{$\begin{array}{l}\text { Group B } \\
(\mathbf{n = 1 0})\end{array}$} & \multirow{2}{*}{ Test of sig. } & \multirow{2}{*}{} \\
\cline { 2 - 5 } & No. & \% & No. & \% & & \\
\hline$<30$ & 2 & 20.0 & 2 & 20.0 & & \\
$31-40$ & 3 & 30.0 & 2 & 20.0 & \multirow{2}{*}{$=1.288$} & ${ }^{\mathrm{MC}} \mathrm{p}=0.870$ \\
$41-50$ & 2 & 20.0 & 4 & 40.0 & & \\
$>50$ & 3 & 30.0 & 2 & 20.0 & & \multirow{2}{*}{0.867} \\
\hline Min. - Max. & $28.0-60.0$ & $24.0-52.0$ & & \\
Mean \pm SD. & $40.90 \pm 11.28$ & $41.70 \pm 9.72$ & $\mathrm{t}=0.170$ & \\
Median & 40.0 & 44.0 & & \\
\hline
\end{tabular}

$\chi^{2}$ : Chi square test MC: Monte Carlo

t: Student t-test

$\mathrm{p}$ : $\mathrm{p}$ value for comparing between the two groups

Group A: Retrograde nail , $\quad$ Group B: Locked plate

Table (2): Comparison between the two studied groups according to time of union

\begin{tabular}{||l|l|l|l|l|l|l||}
\hline \multirow{2}{*}{ Time of union (months) } & \multicolumn{2}{l|}{$\begin{array}{l}\text { Group A } \\
\text { (n= 10) }\end{array}$} & \multicolumn{2}{l|}{$\begin{array}{l}\text { Group B } \\
\text { (n= 10) }\end{array}$} & \multirow{2}{*}{$\begin{array}{l}\text { Test of } \\
\text { sig. }\end{array}$} & \multirow{2}{*}{ p } \\
\cline { 2 - 6 } & No. & \% & No. & \% & \\
\hline$<2$ & 2 & 20.0 & 0 & 0.0 & & \\
$3-6$ & 6 & 60.0 & 7 & 70.0 & $\square \square \square$ & ${ }^{\mathrm{MC}} \mathrm{p}=0.32$ \\
$>6$ & 2 & 20.0 & 3 & 30.0 & $\square \square \square$ & 0 \\
\hline Min. - Max. & $2.0-14.0$ & $3.0-18.0$ & & \\
Mean \pm SD. & $5.50 \pm 4.35$ & $6.80 \pm 4.42$ & $\mathrm{U}=31.0$ & 0.146 \\
Median & 4.0 & 5.50 & & \\
\hline
\end{tabular}

$\chi^{2}$ : Chi square test MC: Monte Carlo, U: Mann Whitney test

$\mathrm{p}$ : $\mathrm{p}$ value for comparing between the two groups

Group A: Retrograde nail , $\quad$ Group B: Locked plate

Table (3):Comparison between the two studied groups according to shortening

\begin{tabular}{||l|l|l|l|l|l|l||}
\hline \multirow{2}{*}{ Shortening } & \multicolumn{2}{|l|}{$\begin{array}{l}\text { Group A } \\
(\mathbf{n = 1 0})\end{array}$} & \multicolumn{2}{l|}{$\begin{array}{l}\text { Group B } \\
(\mathbf{n = 1 0})\end{array}$} & \multirow{2}{*}{$\chi^{\mathbf{2}}$} & \multirow{2}{*}{${ }^{\mathbf{F E}} \mathbf{p}$} \\
\cline { 2 - 7 } & No. & $\mathbf{\%}$ & No. & $\mathbf{\%}$ & & \\
\hline No & 8 & 80.0 & 4 & 40.0 & \multirow{2}{*}{3.333} & \multirow{2}{*}{0.170} \\
\hline
\end{tabular}

$\chi^{2}$ : Chi square test FE: Fisher Exact

$\mathrm{p}$ : $\mathrm{p}$ value for comparing between the two groups

Group A: Retrograde nail, Group B: Locked plate

Table (4):Comparison between the two studied groups according to results

\begin{tabular}{||l|l|l|l|l|l|l||}
\hline \multirow{2}{*}{ Results } & \multicolumn{2}{|l|}{$\begin{array}{l}\text { Group A } \\
(\mathbf{n = 1 0})\end{array}$} & \multicolumn{2}{l|}{$\begin{array}{l}\text { Group B } \\
(\mathbf{n = 1 0})\end{array}$} & \multirow{2}{*}{$\chi^{\mathbf{2}}$} & \multirow{2}{*}{${ }^{\mathbf{M C}} \mathbf{p}$} \\
& No. & \% & No. & \% & & \\
\hline Poor & 2 & 20.0 & 2 & 20.0 & & \\
Fair & 3 & 30.0 & 3 & 30.0 & 0.789 & \multirow{2}{*}{1.000} \\
Good & 3 & 30.0 & 4 & 40.0 & & \\
Excellent & 2 & 20.0 & 1 & 10.0 & & \\
\hline
\end{tabular}

$\chi^{2}$ : Chi square test MC: Monte Carlo, $p$ : $p$ value for comparing between the two groups Group A: Retrograde nail , 


\section{ejhm.journals.ekb.eg}

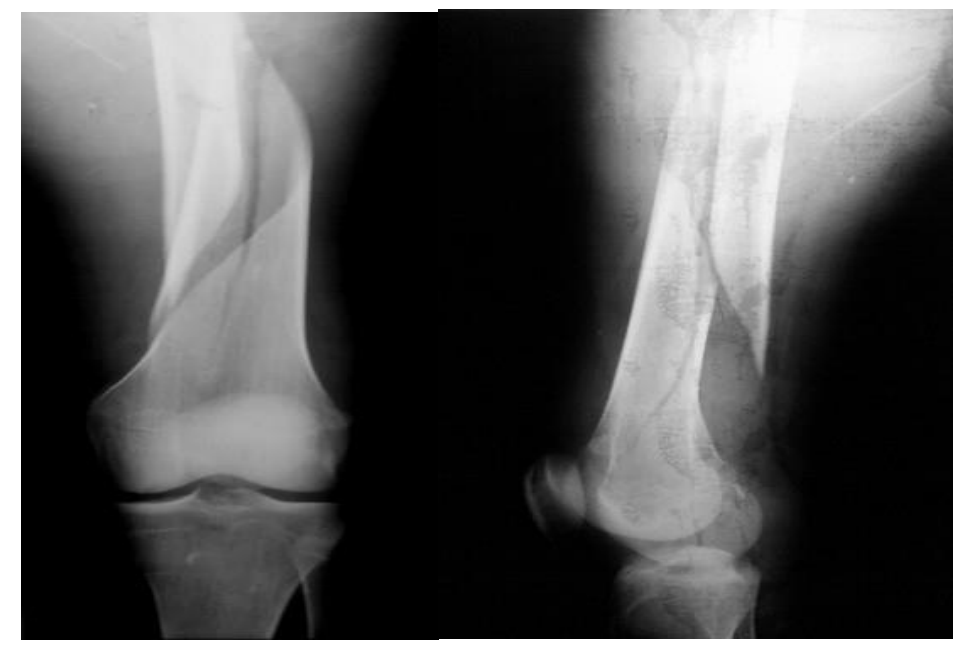

Figure 1a: Preoperative AP and lateral views.
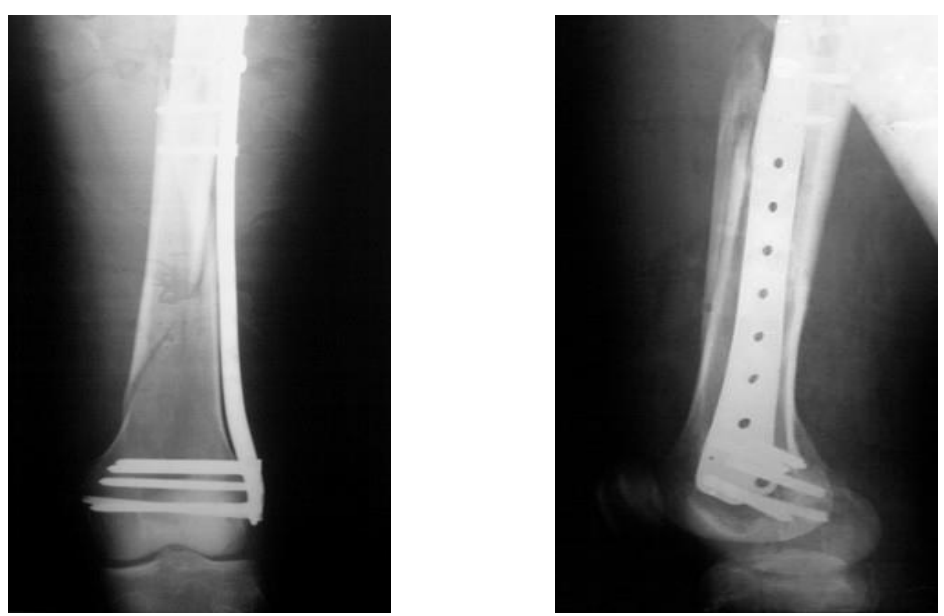

ure 1b: AP and lateral views at 4 weeks.
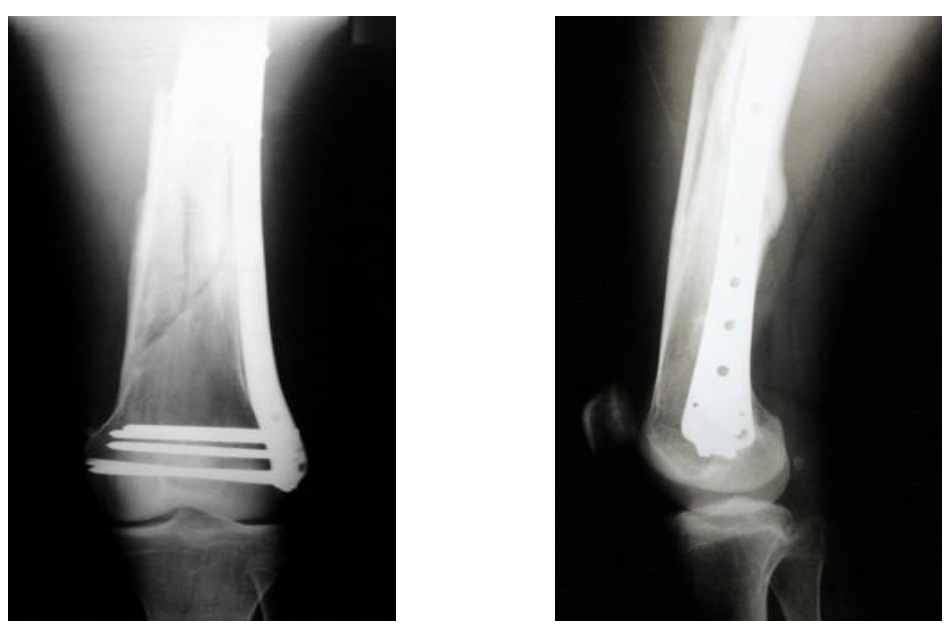

ure 1c: AP and lateral views at 18 months. 


\section{DISCUSSION \\ Age and sex:}

Age in group A ranged between 28-60 years with a mean value $40.90 \pm 11.28$ and in group $B$ ranged between 24-52years with mean a value 41.70 \pm 9.72 . Males in group A were $8(80 \%)$ and females were $2(20 \%)$ while in group B, males were $7(70.0 \%)$ and females were $3(30.0 \%)$. There was no significant statistical difference regarding age and sex in the two studied groups $(\mathrm{P}>0.05)$.

El-kawy et al. ${ }^{[8]}$ in their work studied 23 elderly patients with supracondylar fractures of the femur treated by retrograde femoral nailing. Patients had an average age of 75 years (range between 65 years and 97 years). They concluded that retrograde femoral nailing is a reliable and surgically limited procedure for elderly patients with supracondylar fractures of the femur without intraarticular extension. Although the technique has a high incidence of angular malalignment, the overall functional demands of this age group are not greatly affected by this disadvantage.

\section{Union:}

In group A time of union less than 6 months in 8 cases $(80.0 \%)$ and more than 6 months in 2 cases (20.0\%), While in group B time of union less than 6 months was 7 cases $(70.0 \%)$ and $>6$ months in 3 cases $(30.0 \%)$ There was no significant statistical difference regarding time of union in the two studied groups.

Hierholzer $\boldsymbol{e t}$ al. by clinical and radiographic evaluation reported osseous healing within 6 months following $\mathrm{RN}$ and LISS plating in 104 patients (90.4\%) out of 115 patients. Time to healing was not significantly different between the groups. In the RN group 5 out of 59 patients (9\%) developed nonunion as no bony consolidation of the femoral fracture was observed 6 months after osteosynthesis. In the LISS group, nonunion was observed in 6 out of 56 patients $(12 \%)$. There was no statistically significant difference between the two groups for rate of union [9].

Gupta et al. clinical and radiographic evaluation demonstrated osseous healing within 6 months following retrograde nailing and LCP plating in over $75 \%$ of patients. Average time of union in the LCP group was 6.8 months and in the retrograde nailing group was about 7.4 months. In the retrograde nail group, 5 out of 57 patients (9\%) developed nonunion as no bony consolidation of the femoral fracture was observed 9 months after fixation. In the LCP group, nonunion was observed in 2 out of 46 patients $(4 \%)$. There was no significant statistical difference with respect to time of bone healing among both the groups $(\mathrm{P}<0.05)^{[10]}$.
Shortening:

No shortening in group A was found in8 patients $(80.0 \%)$ and $=2 \mathrm{~cm}$ was 1 patients $(10.0 \%)$ and more than $2 \mathrm{~cm}$ was 1 patients(10.0\%) while in group B, No shortening was found in7 patients $(70.0 \%)$ and less than $2 \mathrm{~cm}$ was found in 2 patients $(20.0 \%)$ and $>2 \mathrm{~cm}$ was one patient $(10.0 \%)$. There was no significant statistical difference regarding shortening in the two studied groups $(\mathrm{P}>0.05)$.

The results obtained were found comparable to the results of other studies. Gupta et al. conducted a retrospective study to 103 patients with distal femoral fracture who had been treated by retrograde intramedullary Interlocking (IMIL) nailing $(n=57)$ and Locking Compression Plating $(\mathrm{LCP})(\mathrm{n}=46)$. The results showed no statistically significant differences between the nailing and the LCP groups as regards time to osseous healing, rate of nonunion and postoperative complications. In the present study, we have noticed no complications in the patients with type A fractures treated with LCP plating. The limitation of the study is that the patients were not randomized to each group ${ }^{[10]}$.

Hierholzer et al conducted a retrospective study to 115 patients with distal femoral fracture, 59 patients were treated with RN and 56 patients with LISS plate osteosynthesis. No statistically significant differences between the nail and the LISS group as regards time to osseous healing, rate of nonunion and postoperative complications ${ }^{[9]}$.

\section{CONCLUSION}

It could be concluded that retrograde nailing provides a favorable intramedullary stability and stable callus and may be successfully implanted in segmental fractures of the lower extremity. Persistent knee pain and inability to use in type $\mathrm{C}$ fractures are the main limiting factors of retrograde nail. LCP was associated with less morbidity in terms of persistent knee pain and better range of movements than retrograde nailing. Locked plating may be utilized for all distal femur fractures including type $\mathrm{C}$ fractures and osteoporotic fractures.

The complications encountered in this study were joint stiffness, shortening and knee pain.

\section{REFERENCES}

1. Khan AM, Tang QO, Spicer D (2017): The epidemiology of adult distal femoral shaft fractures in a central London major trauma centre over five years. The open orthopaedics journal,11:1277.

2. Zhao Z, Li Y, Ullah K, Sapkota B, Bi H, Wang - (2018): The antegrade angle-stable locking intramedullary nail for type-C distal femoral fractures: a thirty four case experience. Int Orthop.,42(3):659-65. 
3. Sanders R, Swiontkowski M, Rosen H, Helfet D (1991): Double-plating of comminuted unstable fractures of the distal part of the femur. JBJS.,73(3):341-6.

4. Schatzker J (1998): Fractures of the distal femur revisited. Clinical orthopaedics and related research, (347):43-56.

5. Du YR, Ma JX, Wang S, Sun L, Wang Y, Lu B (2019): Comparison of Less Invasive Stabilization System Plate and Retrograde Intramedullary Nail in the Fixation of Femoral Supracondylar Fractures in the Elderly: A Biomechanical Study. Orthop Surg.,11(2):311-7.

6. Krettek C, Müller M, Miclau T (2001): Evolution of minimally invasive plate osteosynthesis (MIPO) in the femur. Injury,32:1423.
7. Massoud EL (2015): Fixation of distal femoral fractures: Restoration of the knee motion. Ulus Travma Acil Cerrahi Derg.,21(3):197-203.

8. El-Kawy S, Ansara S, Moftah A, Shalaby H, Varughese V (2007): Retrograde femoral nailing in elderly patients with supracondylar fracture femur; is it the answer for a clinical problem?. International orthopaedics,31(1):83.

9. Hierholzer C, von Rüden C, Pötzel T, Woltmann A, Bühren V (2011): Outcome analysis of retrograde nailing and less invasive stabilization system in distal femoral fractures: a retrospective analysis. Indian journal of orthopaedics, 45(3):243.

10. Gupta S, Govindappa C, Yalamanchili R4 (2013): Outcome of retrograde intramedullary nailing and locking compression plating of distal femoral fractures in adults. OA Orthopaedics,1(3):23. 